\title{
The Reliability Model on the Burned Failure of Molded Case Circuit
}

\author{
Xue yang ${ }^{1, a}$, Cheng Yangchun ${ }^{2, b}$, Zhang penghe ${ }^{1, c}$, Xu yinghui ${ }^{1, d}$, Zhang \\ Baoliang $^{1, e}$, Xiong Dezhi ${ }^{3, f}$, Dou Zhengzhou ${ }^{5,9}$ and Li Wenwen ${ }^{5, h}$ \\ ${ }^{1}$ Institute of Measurement, China Electric Power Research Institute, Haidian District, Beijing ,100192, \\ China. \\ ${ }^{2}$ Beijing key laboratory of high voltage and EMC, North China Electric Power University, Beijing, \\ 102206, China \\ ${ }^{3}$ Metrology Center of State Grid Hunan Electric Power Company, Changsha, 410007, China. \\ ${ }^{4}$ Henan XJ Metering Co.Ltd, Xuchang, 461000, China. \\ ${ }^{5}$ Stade Grid Jibei Electric Power Company Limited Power Research Institute, Beijing ,102208, \\ China. \\ axueyang3@epri.sgcc.co.cn, ${ }^{b}$ chych@ncepu.edu.cn, ${ }^{\mathrm{c}}$ zhangpenghe@epri.sgcc.co.cn, \\ dxuyinghui@epri.sgcc.co.cn, ${ }^{\mathrm{e}}$ zhangbaoliang@epri.sgcc.co.cn, ${ }^{\mathrm{f}} 404451135 @ q q . c o m$, \\ 5534414471@qq.com, '821328633@qq.com.
}

Keywords: Molded case circuit breaker; burned failure; reliability; aging test.

Abstract. Low voltage molded case circuit breaker is widely used in the low voltage distribution system of customers. Along with the revolution of the electric power grid, Low voltage molded case circuit breaker in resident house takes more important intelligent function except of its traditional function. In the recent standards, it is lack of the items about the reliability of the wire terminal of the breaker. But according to the results of the survey to the failure of LVMCB, the burned failure has great percentage. In this paper, the main mechanism of the burned failure of the terminal is researched, which is described as the loss of heat balance. Based on this mechanism, the reliability model focused on the burned failure is established, in which the random on the quality of the breaker, the random on the load of the breaker, and the characteristic degradation of the breaker are considered. The probability density distribution function, heat balance equation and iteration calculation are used to calculate the reliability. Finally, the accelerated aging methods and parameters, such as high temperature aging and its test temperature, high current aging and its current and duration time, are induced to carry out the reliability test.

\section{Introduction}

Low-voltage molded case circuit breaker (LVMCB) is one kind of breaker with very compact structure, small capacity, and plastic shell. It has become a great category from one branch of the low voltage breaker. From the IEC898 and GB10963, the low-voltage molded case circuit breaker is the breaker with operating voltage below $400 \mathrm{~V}(\mathrm{AC}, 50 \mathrm{~Hz}$ or $60 \mathrm{~Hz})$, current below $125 \mathrm{~A}$, and ultimate short-circuit breaking capacity below 25000A. It is one kind of important switch device, which is widely used in the low voltage distribution system. It is used in high-rise buildings, machine tool industry and business system, to protect the electrical equipment when over current, short circuit or low voltage happens. It is used so widely in civilian field that the International Electrotechnical Commission (IEC) name it as circuit-Breakers for over-current Protection for Household and similar Installation [1].

In the great plan of strong and smart power grid in China, the LVMCB in resident house takes more important intelligent function, except its traditional function such as cutting off the short circuit current. The intelligent function of the LVMCB will include switching on or cutting off the electric power according to the payment conditions of users or the electricity supply of the grid, and collecting the electricity information and demand of users. The smart home and civil demand will deeply take part in the operation of the whole power grid. Thus, the reliability of the LVMCB 
becomes more important.

In order to meet the demand of the new industrial revolution, the new generation LVMCB has great improvement in cut off capability, intelligentization, and reliability [2-6].The test and detection device for reliability are developing to auto detect and record the condition of samples. National standard GB/Z 22074-2008 was revised to specify and restrict the reliability test method for moulded case circuit breakers. In this standard, the reliability is identified as operation failure rate, instantaneous protection success ratio, and overload protection success ratio[7].

LVMCB mainly consists of contact system, release system, operation system, and attachment system. In the standard GB/Z 22074-2008 and other standards, the reliability indicators and their test methods are focus on the contact system, release system, and operation system. But according to statistic data, there are lots of failures on the attachment system, such as the wire terminal burning. There is not specification and test method to deal with this kind of failure.

In this paper, the failure on the wire terminal is discussed. The corresponding reliability model and accelerated aging test method are established.

\section{Burned failure of Molded Case Circuit Breaker}

\section{A. Burned Failure of Traditional Molded Case Circuit Breaker}

The data from January to May in 2014 were collected. The total fault cases are 64418, in which there are 44532 breakers burned, 6312 breakers could not switch on after switch off, 16552 breakers made wrong operation or others. The percentage of each failure modes are $69.13 \%, 9.80 \%, 25.69 \%$ respectively, as shown in Fig.1.

\section{B. Burned Failure of Intelligent Molded Case Circuit Breaker}

In the second area, the outside load circuit breaker is used together with the intelligent electric energy meter. There are total 9.8 million breakers in the serves. Most of them are the 63A rate breaker. The failure cases in this area from 2011 to 2015 were collected. If the failure of time mismatch between the switch and the power meter is ignored, the Burned of the switch and print circuit board is $42.75 \%$ of the total failures cases.

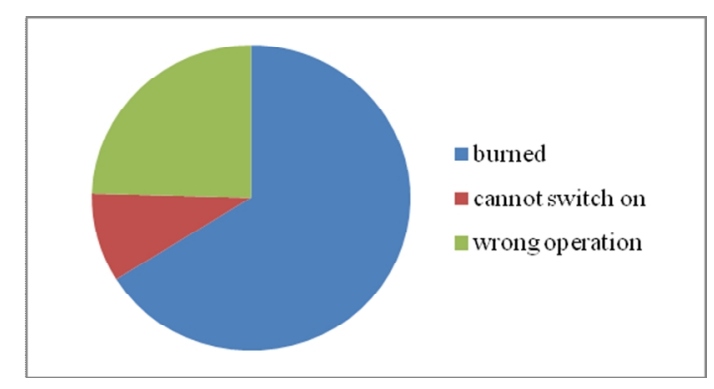

Fig. 1 The percentage of each failure modes of traditional breaker wire terminal

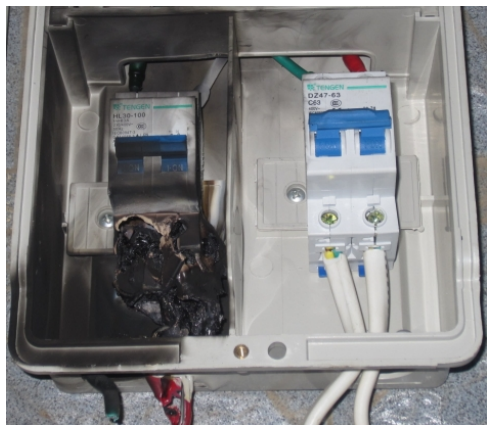

Fig.2 the burned

\section{Mechanism of the Burned Failure}

The burned failure is the most important failure mode of the molded case circuit breaker. In Fig.2 there are some examples of burned breakers. The main reason that leading to the breaker burned is as following. The multi-strand aluminum wire is used to connect the current into the breaker. The wire is not specially processed, so that the wire is loose when it is installed into the terminal. Therefore, the contact area between the wire and the terminal is too small. It results in higher temperature. The high temperature will accelerate the oxidization of the aluminum, and then decease the contact area, increase the contact resistance. The oxidizations of the aluminum wire are including the chemical reaction with oxygen, and the chemical reaction with the cooper terminal on the breaker. This bad cycle finally leads to the burn of the wiring terminal. 
Some time, the bad quality of the breaker, such as the wire terminal is too thin to withstand the normal current, or the thermal transfer characteristic of the breaker is too bad to transmit heat out, accelerates above oxidization of the aluminum.

\section{Reliability Model For the Burned Failure}

\section{A. OrgThe Heat Balance}

According to above analysis, the mechanism of burned failure is that the unbalance heat leads to high temperature. When the high contact resistance meets with the degradation of the thermal transfer characteristic and overload, the heat will become unbalance. The Eq.1 can describe this balance.

$I^{2} R_{s}(t)=Q_{c}+Q_{r}+Q_{s}$

Where

I-current in the wire, A.

Qs_— heat loss through transfer, W.

Qc_- heat loss through the air convection, W.

$\mathrm{Qr}$ - heat loss through radiation, $\mathrm{W}$.

Rs $(\mathrm{t})$ - contact resistance, $\Omega$.

t—- time

Thinking about the situation of the LVMCB, the Qs, Qc, Qr can be calculated through the following equations.

$$
\begin{aligned}
& Q_{s}=k_{s}\left(T-T_{a}\right) \\
& Q_{c}=k_{c} \rho_{f}^{0.5}\left(T-T_{a}\right)^{1.25} \\
& Q_{r}=A \varepsilon \sigma\left[(T+273)^{4}-\left(T_{a}+273\right)^{4}\right]
\end{aligned}
$$

Where,

ks is the thermal transfer coefficient of the wire terminal.

$\mathrm{T}$ is the temperature of the terminal.

$\mathrm{Ta}$ is the temperature of the environment.

$\mathrm{kc}$ is the air convection coefficient of the wire terminal, which is relevant with the surface area of the wire terminal.

A is the surface area of the wire terminal

$\rho_{f}$ is the air density.

$\varepsilon$ is the surface radiation coefficient of the of the wire terminal, which is about 0.2 to new terminal and about 0.9 to aged terminal.

$\sigma$ is the Boltzmann constant, which is $5.67 * 10-8, \mathrm{~W} /(\mathrm{m} 2 \mathrm{~K} 4)$.

From Eq. 1 the relationship among the current $\mathrm{I}$, the contact resistant $\mathrm{Rs}(\mathrm{t})$ and the temperature $\mathrm{T}$ is decided. Assuming that the maxim tolerated temperature of the breaker is Tm, when $\mathrm{T}$ exceeds $\mathrm{Tm}$, burning will happen. So, when the value of the Tm is decided, the maxim tolerated current Im will be decided by $\operatorname{Rs}(\mathrm{t})$.

\section{B. Reliability Calculation}

According to Eq.1, when the load of the breaker I exceed Im, failure takes place. So, the reliability $\mathrm{R}$ of the breaker is equal to the possibility that $\mathrm{I}$ is less than $\mathrm{Im}$.

$$
R=p\left(I \mid I<I_{m}\right)
$$

In fact, to a certain breaker, its Im is unknown. But it has explicit statistic characteristic, described by its strength rate density distribution function $\mathrm{f}(\mathrm{Im})$. This random is from the manufacture. The load of the breaker is also random, but also has statistic characteristic described by its density distribution function $\mathrm{h}(\mathrm{I})$. Therefore, the reliability is calculated as Eq.6, which can be described by Fig.3. 


$$
R=\int_{-\infty}^{+\infty} h(I)\left[\int_{I}^{+\infty} f\left(I_{m}\right) d I_{m}\right] d I
$$

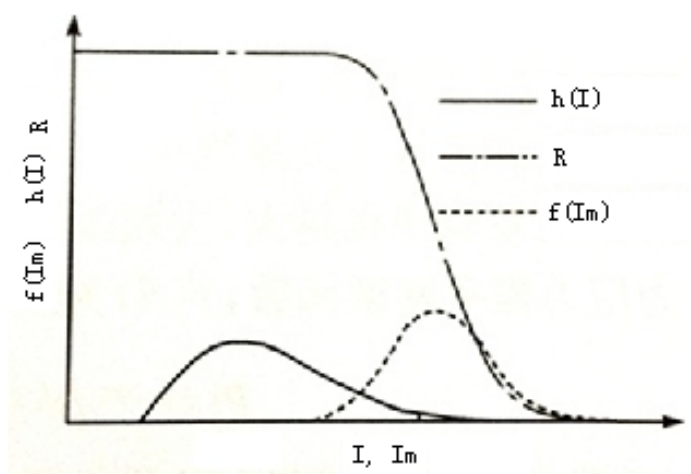

Fig.3 The density distribution function

\section{Degradation of the Breaker}

Along with the time, the aluminum wire is oxidizing, so that the contact resistance $\mathrm{Rs}(\mathrm{t})$ is increasing. The oxidization process is relevant with the temperature. Higher temperature leads to higher oxidizing speed. And higher current I leads to higher temperature. That is, the Rs(t) is relevant with time and load.

Chemical reaction rates have been commonly expressed by the A.rrhenius Relation, so that the change rate of $\mathrm{Rs}(\mathrm{t})$ can be described by the differential equation Eq.7.

$$
\frac{d R_{s}(t)}{d t}=A_{0} \cdot \exp \left(-\frac{b}{k T}\right)
$$

Where,

$\mathrm{k}$ is the Boltzmann constant, which is $8.617 * 10-5 \mathrm{eV} \square$.

$\mathrm{T}$ is the absolute temperature of the terminal.

$\mathrm{A} 0$ is a constant.

$\mathrm{t}$ is the reaction time.

$b$ is the activation energy.

The temperature $\mathrm{T}$ is decided by $\mathrm{Rs}(\mathrm{t})$ and $\mathrm{I}$ through Eq.1. In a small time interval $\Delta \mathrm{t}$, the $\mathrm{Rs}(\mathrm{t})$ is constant, so that the $\mathrm{T}$ is decided by current $\mathrm{I}$. When the I has random characteristic described by $\mathrm{h}(\mathrm{I})$. Then, at a certain time $\mathrm{t}$, the $\mathrm{T}$ is described by the following equation Eq.8.

$$
T=\int_{-\infty}^{+\infty} h(I) f_{T}\left(I, R_{s}(t), T_{a}\right) d I
$$

Where the function $f_{T}\left(I, R_{s}(t), T_{a}\right)$ is derived by Eq. 1 to calculate T from I, Rs(t) and Ta.

Then, at a certain time $t$, the contact resistance Rs $(\mathrm{t})$ will be as following equation Eq.9, in which $\mathrm{T}$ is as in Eq.8. This equation should be calculated by iteration method.

$$
R_{s}(t)=\int_{0}^{t} A_{0} \cdot \exp \left(-\frac{b}{k T}\right) d t
$$

Along with the change of $R s(t)$, the maxim tolerated current Im of the breaker will also change. It is assumed that the expectation value of Im change, but the variance of Im does not change, so that the reliability R in Eq.6is changed to Eq.10.

$$
R=\int_{-\infty}^{+\infty} h(I)\left[\int_{I}^{+\infty} f\left(I_{m}\left(R_{s}(t)\right)\right) d I_{m}\right] d I
$$

Where $I_{m}\left(R_{s}(t)\right)$ is the function that calculating Im through (1) with $\mathrm{R}(\mathrm{t})$. 


\section{Conclusion}

According to the results of the survey to the failure of LVMCB, the burned failure has great percentage. The main mechanism of the burned failure is that the heat balance is becoming loss due to the increasing contact resistance between the aluminum wire and the copper terminal of the breaker, which is because of the long term oxidization process of the aluminum wire.

Based on the heat balance equation, the reliability model focused on the burned failure is established, in which the random on the quality of the breaker, the random on the load of the breaker, and the characteristic degradation of the breaker are considered. The probability density distribution function, heat balance equation and iteration calculation are used to calculate the reliability. Finally, the accelerated aging methods and parameters, such as high temperature aging and its test temperature, high current aging and its current and duration time, are induced to carry out the reliability test.

\section{Acknowledgements}

This work was financially supported by the State Grid Company, Project JLB (17201500227).

\section{References}

[1] Electical Accessories - Circuit-Breakers for Overcurrent Protection for Household and similar Installation - part 1: Circuit-Breakers for a.c. Operation, National Standard of China GB 10963.1-2005/IEC 60898-1:2002, July 2005.

[2] FENG Jun , LI Haibing, "Research on Intelligentization of Moulded Case Circuit Breaker", Low Voltage Electrical Appliances, No.7, pp.26-28, 2013.

[3] TAO Bing kun, WANG Xin, MENG Fan-hua, LIU Hai-li, "Design of an intelligent breaker based on TMS 320F2812", Power supply technology, Vo1.38, N0.4, pp.771-773, April 2014.

[4] Liu J, Fan T, Tong K. "Research of network technology for Intelligent Circuit Breaker Controller". Journal of Zhejiang University: Science A, Vol.8, No.3, pp.464-468, 2007.

[5] Xiqing Yan, "The Hardware Design and Reliability Study of Intelligent Low-voltage Molded Case Circuit Breaker System”, Master dissertation, Hangzhou Dianzi University, 2013.

[6] Guoqiang Ji, "Research on intelligent molded case circuit breaker based on embedded ARM", Master dissertation, Hebei University of Technology, 2013.

[7] Reliability test method for moulded case circuit breakers, National Standard of China GB/Z 22074-2008, June, 2008. 